\title{
Study of Red Blood Cell Indices and Biochemical Parameters of Mineral Bone Disorders in Hemodialysis Patients
}

\author{
Alhoussein Alsayed AbdelAal*, Alshabrawy M. Abdelnabi
}

Department of Internal Medicine, Faculty of Medicine, Zagazig University, Egypt

* Corresponding author: Alhoussein Alsayed AbdelAal, Mobile: (+2) 01022073791, E mail: alhala1982@gmail.com

\begin{abstract}
Background: Chronic kidney disease (CKD) is a worldwide public health problem and a major cause of suffering and having a reduced quality of life for those affected.

Objective: We aimed to study the changes in red blood cell indices and mineral bone metabolism in hemodialysis patients and to explore the correlation between these studied parameters.

Patients and Methods: This is a case control study included 55 adult patients with end stage renal disease on maintenance hemodialysis as well as $\mathbf{5 5}$ healthy individuals as a control group. All participants were subjected to laboratory investigations included complete blood count and serum levels of creatinine, urea, total calcium, albumin, phosphate and intact parathyroid hormone (iPTH).

Results: Our study showed that hemoglobin $(\mathrm{Hb})$, hematocrit and red blood cell count were significantly reduced in the hemodialysis patients ( $\mathrm{P}<0.001$ for all). Regarding mean corpuscular volume, mean corpuscular hemoglobin and mean corpuscular hemoglobin concentration, no significant differences were found between the hemodialysis patients and the control group $(\mathrm{P}=0.362,0.116,0.22$, respectively). In the hemodialysis group, the albumin-corrected serum calcium level was significantly lower while the serum phosphate and iPTH levels were significantly higher compared to the control group $(\mathrm{P}<0.001$ for all $)$. Hb was inversely correlated with serum iPTH $(r=-0.359, \mathrm{P}=0.007)$ and serum phosphate $(\mathrm{r}=-0.570, \mathrm{P}<0.001)$ in the hemodialysis group and was inversely correlated with serum phosphate $(\mathrm{r}=-$ $0.495, \mathrm{P}<0.001)$ in the control group.

Conclusion: Hemodialysis patients are at high risk of anemia, hypocalcemia, hyperphosphatemia and hyperparathyroidism. In hemodialysis patients, an association was found between anemia and each of hyperphosphatemia and hyperparathyroidism.
\end{abstract}

Keywords: Anemia, Chronic kidney disease, Hemodialysis, Mineral bone disorder.

\section{INTRODUCTION}

Chronic kidney disease $(\mathrm{CKD})$ is recognized as a global public health problem inflicting huge medical and economic burdens on societies and health care organizations with an estimated prevalence of $13.4 \%$ universally (1). Although healthcare resources allocated for management of CKD have significantly increased in past years, patients with CKD continue to have a significant decrease of life expectancy ${ }^{(2)}$. With the progression of CKD, a wide range of physiological processes are altered by the progressive decline in glomerular filtration rate. Hematological parameters particularly red blood cell (RBC) indices are commonly affected giving rise to anemia ${ }^{(3)}$. Another common complication of CKD is the deterioration in mineral homeostasis manifesting as disturbance of serum concentrations of phosphate and calcium as well as changes in the circulating levels of parathyroid hormone (PTH) resulting in mineral bone disorder ${ }^{(4)}$. Several investigators have proposed a link between anemia and mineral metabolism. Conversely, other authors have failed to detect an association between anemia and PTH.

The present study aimed to evaluate red blood cell indices and mineral metabolism indicators in hemodialysis patients and to assess the association between these parameters.

\section{PATIENTS AND METHODS}

This study was a case control study that has conducted in Nephrology Unit, Internal Medicine Department, Faculty of Medicine, Zagazig University Hospitals between May 2019 and April 2020.

The present study included 55 patients with end stage renal disease (ESRD) on maintenance hemodialysis for more than 3 months. Patients were selected randomly for study participation. The age range of patients was 18 to 70 years.

The study excluded patients with other comorbid conditions such as chronic liver disease, hypersplenism, autoimmune diseases, obstructive airway disease, thyroid gland dysfunctions, malignancy, recent myocardial infarction or stroke, history of bleeding as hematemesis or melena, primary known hematological disease, HIV infection and patients on medications such as bisphosphonates or warfarin. Pregnant or lactating women, those who received iron, erythropoietin, calcium or vitamin D therapy in any form within the last 3 months, patients who had blood transfusion in the past 3 months, patients with active infection, and patients with known parathyroid disorder, metabolic bone diseases or anemia with definite etiology were also excluded from the study. 
55 healthy participants matched for age and sex had been included in the study as a control group.

All participants were subjected to full history taking, complete clinical examination and laboratory investigations.

\section{Sampling and laboratory investigations:}

Three milliliters of venous blood was collected from each participant using disposable plastic syringes (for hemodialysis patients, blood samples were collected before starting dialysis session). One milliliter of collected blood was added to EDTA to perform complete blood picture (CBC) using Erma Automated Blood Count Machine (Tokyo, Japan).

The other two milliliters of blood were allowed to clot for 30 minutes then were centrifuged for $15 \mathrm{~min}$ at $3000 \mathrm{rpm}$ for separation of serum. The serum sample was sent to the laboratory within 2 hours of collection. Intact PTH (iPTH) was measured by chemiluminescent microparticle immunoassay using TosohAIA-360 Automated Immunoassay Analyzer (Tosoh, Tokyo, Japan). Serum phosphate, total calcium, albumin, creatinine, and urea were measured by spectrophotometry using the Beckman DxC800 general chemistry analyzer (Beckman Coulter, Fullerton, CA, USA).

Albumin-corrected serum calcium (calcium ${ }_{\mathrm{Alb}}$ ) was calculated as [(4-albumin)*0.8] + total serum calcium, with serum albumin expressed in $\mathrm{g} / \mathrm{dl}$ and total serum calcium in $\mathrm{mg} / \mathrm{dl}^{(5)}$.

\section{Ethical approval:}

We obtained approval for performing this study from the Institutional Review Board, Zagazig Faculty of Medicine and written informed consent was taken from all enrolled individuals.

\section{Statistical analysis}

All data were collected, tabulated, and statistically analyzed using SPSS 22.0. Categorical data were described as percentages and continuous data were described as means \pm standard deviations. Percentages of categorical variables were compared using Chi-square test $\left(\chi^{2}\right)$.

Continuous variables were checked for normality by Kolmogorov-Smirnov test. Independent Student ttest was used to compare continuous variables. All statistical comparisons were two-tailed. P-value $<0.05$ was considered to be statistically significant and Pvalue $<0.01$ was considered to be highly statistically significant. Correlations between variables were done by using the Pearson correlation coefficient.

\section{RESULTS}

Our study included 110 individuals; 55 hemodialysis patients and 55 healthy individuals matched for age and sex. Mean age was 51.63 years. Each group was consisted of 27 males and 28 females (Table 1).

Table (1): Demographic data of the studied groups

\begin{tabular}{|c|c|c|c|c|c|c|}
\hline \multirow{2}{*}{ Parameter } & \multicolumn{2}{|c|}{$\begin{array}{l}\text { Control group } \\
(\mathbf{N}=55)\end{array}$} & \multicolumn{2}{|c|}{$\begin{array}{l}\text { Hemodialysis group } \\
(\mathbf{N}=55)\end{array}$} & \multirow[t]{2}{*}{ Test } & \multirow[t]{2}{*}{ p-value } \\
\hline & No. & $\%$ & No. & $\%$ & & \\
\hline \multicolumn{7}{|l|}{ Gender } \\
\hline Male & 27 & 49.1 & 27 & 49.1 & \multirow{2}{*}{$\chi^{2}=0$} & \multirow{2}{*}{1} \\
\hline Female & 28 & 50.9 & 28 & 50.9 & & \\
\hline \multicolumn{7}{|l|}{ Age (years) } \\
\hline Mean \pm SD & \multicolumn{2}{|c|}{$51.3 \pm 12.40$} & \multicolumn{2}{|c|}{$51.96 \pm 12.31$} & $t=0.28$ & 0.78 \\
\hline
\end{tabular}

$\mathrm{N}$ : number of subjects; $\mathrm{t}$ : independent student t-test; $\chi 2$ : Chi-square test

Regarding RBC indices, the hemodialysis group showed significantly lower hemoglobin ( $\mathrm{Hb}$ ), hematocrit and RBC count and significantly higher red cell distribution width (RDW) compared to the control group as shown in Table 2. 
Table (2): Comparison between the studied groups regarding $\mathrm{RBC}$ indices

\begin{tabular}{|c|c|c|c|c|}
\hline Parameter & $\begin{array}{l}\text { Control group } \\
(\mathrm{N}=55)\end{array}$ & $\begin{array}{l}\text { Hemodialysis group } \\
(\mathrm{N}=\mathbf{5 5})\end{array}$ & Test & $P$ value \\
\hline \multicolumn{5}{|c|}{ Hemoglobin g/dL } \\
\hline Mean \pm SD & $12.70 \pm 0.76$ & $10.09 \pm 1.41$ & $\mathrm{t}=12.08$ & $<0.001$ \\
\hline \multicolumn{5}{|c|}{ Hematocrit \% } \\
\hline Mean \pm SD & $38.82 \pm 2.87$ & $31.79 \pm 4.58$ & $t=9.65$ & $<0.001$ \\
\hline \multicolumn{5}{|c|}{ RBC count $\left(10^{6} / \mu \mathrm{l}\right)$} \\
\hline Mean \pm SD & $4.87 \pm 0.36$ & $3.75 \pm 0.55$ & $\mathrm{t}=12.67$ & $<0.001$ \\
\hline \multicolumn{5}{|c|}{ MCV (femtoliters) } \\
\hline Mean \pm SD & $86.2 \pm 7.8$ & $87.4 \pm 5.8$ & $t=0.92$ & 0.362 \\
\hline \multicolumn{5}{|c|}{ MCH (Picogram/cell) } \\
\hline Mean \pm SD & $28.22 \pm 0.56$ & $27.65 \pm 2.61$ & $\mathrm{t}=1.58$ & 0.116 \\
\hline \multicolumn{5}{|c|}{ MCHC (g/dL) } \\
\hline Mean \pm SD & $34.57 \pm 0.56$ & $34.37 \pm 1.07$ & $\mathrm{t}=1.23$ & 0.222 \\
\hline \multicolumn{5}{|l|}{ RDW (\%) } \\
\hline Mean \pm SD & $13.44 \pm 0.85$ & $15.08 \pm 1.82$ & $t=6.05$ & $<0.001$ \\
\hline
\end{tabular}

$\mathrm{N}$ : number of subjects; MCH: mean corpuscular hemoglobin; MCHC: mean corpuscular hemoglobin concentration; MCV: mean corpuscular volume; RDW: red cell width distribution; SD: standard deviation; t: independent student t-test

While comparing the two studied groups regarding kidney function tests and biochemical parameters of mineral bone disorders, there were statistically significant differences in serum levels of creatinine, urea, calcium Alb$_{\text {, }}$, phosphate and serum iPTH between the two studied groups as shown in Table 3.

Table (3): Comparison between the studied groups regarding kidney function tests and biochemical parameters of mineral bone disorders

\begin{tabular}{|c|c|c|c|c|}
\hline Parameter & $\begin{array}{l}\text { Control group } \\
(\mathrm{N}=55)\end{array}$ & $\begin{array}{l}\text { Hemodialysis group } \\
(\mathrm{N}=55)\end{array}$ & Test & P value \\
\hline \multicolumn{5}{|c|}{ Serum creatinine $\mathbf{m g} / \mathrm{dl}$} \\
\hline Mean \pm SD & $0.85 \pm 0.11$ & $10.25 \pm 2.51$ & $t=27.75$ & $<0.001$ \\
\hline \multicolumn{5}{|c|}{ Blood urea mg/dl } \\
\hline Mean \pm SD & $27.94 \pm 5.07$ & $150.4 \pm 28.06$ & $\mathrm{t}=31.85$ & $<0.001$ \\
\hline \multicolumn{5}{|c|}{ Calcium $_{\text {Alb }} \mathrm{mg} / \mathrm{dl}$} \\
\hline Mean \pm SD & $9.71 \pm 0.34$ & $8.99 \pm 0.76$ & $t=6.41$ & $<0.001$ \\
\hline \multicolumn{5}{|c|}{ Serum phosphate mg/dl } \\
\hline Mean \pm SD & $3.91 \pm 0.27$ & $5.61 \pm 1.13$ & $\mathrm{t}=10.85$ & $<0.001$ \\
\hline \multicolumn{5}{|c|}{ Serum iPTH pg/ml } \\
\hline Mean \pm SD & $32.45 \pm 5.66$ & $562.3 \pm 86.56$ & $\mathrm{t}=10.16$ & $<0.001$ \\
\hline
\end{tabular}

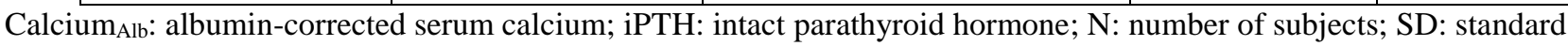
deviation; $\mathrm{t}$ : independent student t-test

As regards the relationship between $\mathrm{Hb}$ and biochemical parameters of mineral bone disorders, the present study showed that $\mathrm{Hb}$ was inversely correlated with both serum iPTH and serum phosphate in the hemodialysis group while in the control group there was a statistically significant inverse correlation between $\mathrm{Hb}$ and serum phosphate only (Table 4 and Figures 1-3).

Table (4): Correlation between hemoglobin and biochemical parameters of mineral bone disorders in the hemodialysis group and the control group

\begin{tabular}{|l|l|l|l|l|}
\hline \multirow{2}{*}{ Parameter } & \multicolumn{3}{|l|}{ Hemoglobin } \\
\cline { 2 - 5 } & \multicolumn{2}{|l|}{ Hemodialysis group } & \multicolumn{2}{l|}{ Control group } \\
\cline { 2 - 5 } & $\mathbf{r}$ & $\mathbf{P}$ & $\mathbf{r}$ & $\mathbf{p}$ \\
\hline Calcium $_{\text {Alb }}$ & 0.26 & 0.055 & 0.134 & 0.329 \\
\hline Serum phosphate & -0.570 & $<0.001$ & -0.495 & $<0.001$ \\
\hline iPTH & -0.359 & 0.007 & -0.123 & 0.371 \\
\hline
\end{tabular}

Calcium ${ }_{\text {Alb: }}$ albumin-corrected serum calcium; iPTH: intact parathyroid hormone 
https://ejhm.journals.ekb.eg/

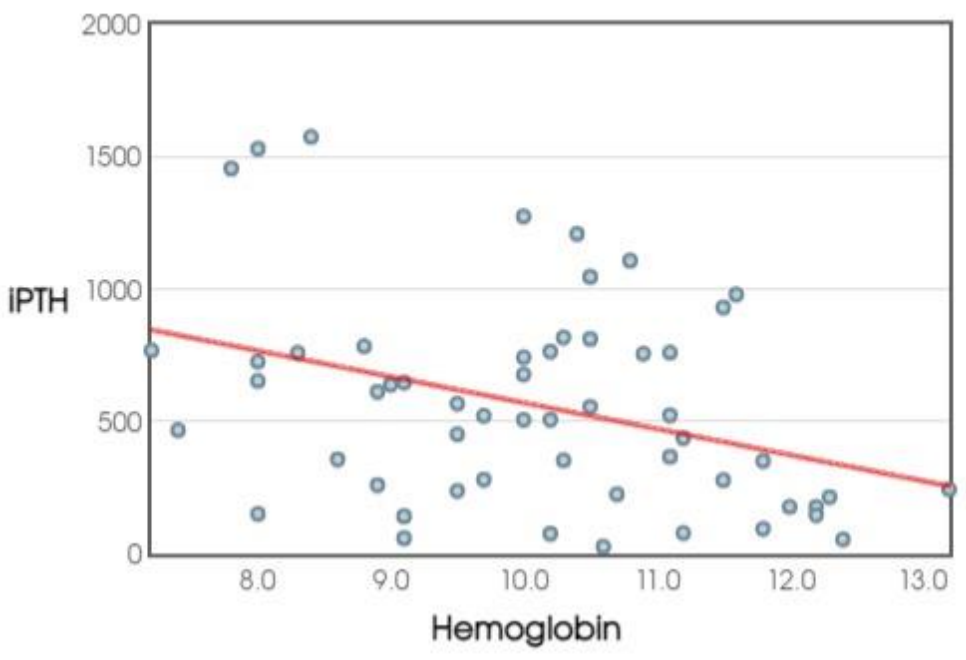

Figure (1): Correlation between hemoglobin and iPTH in the hemodialysis group.

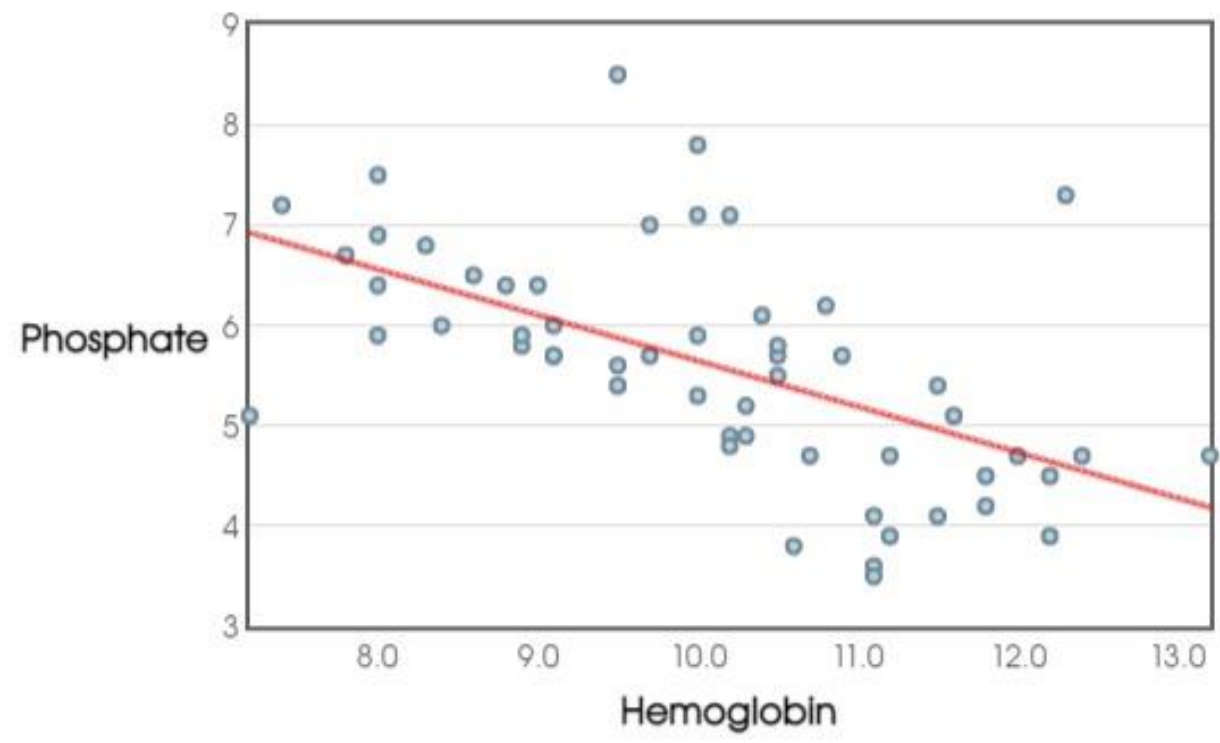

Figure (2): Correlation between hemoglobin and phosphate in the hemodialysis group.

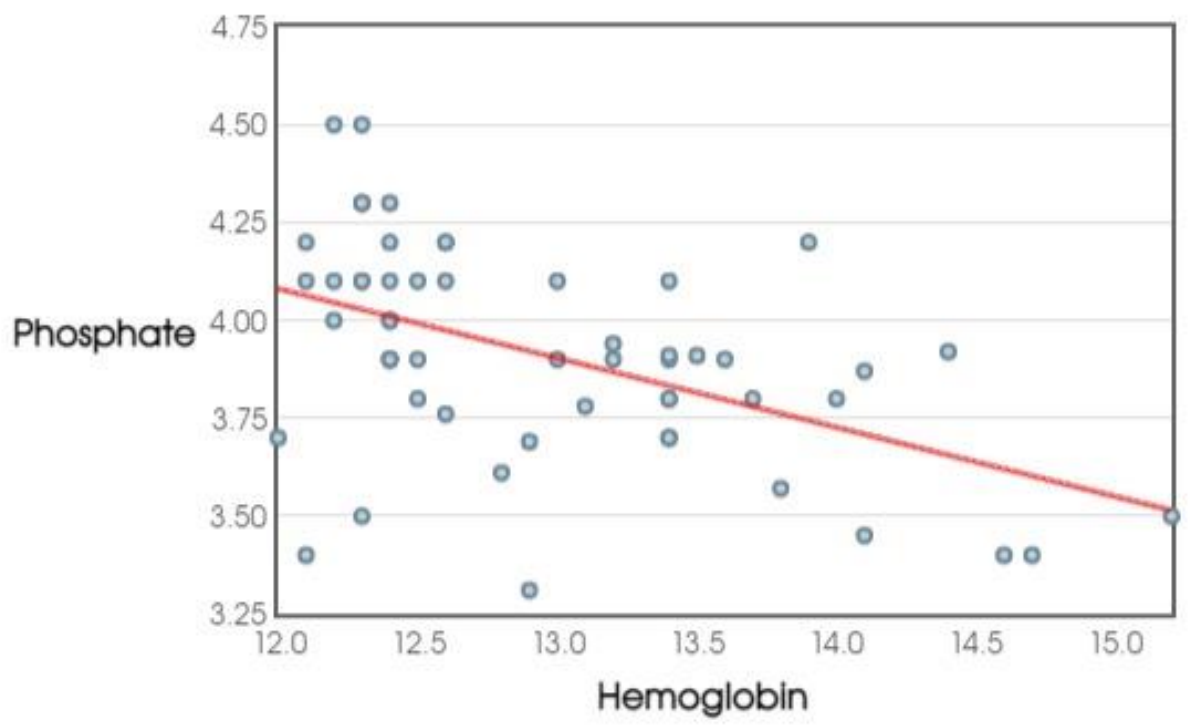

Figure (3): Correlation between hemoglobin and phosphate in the control group 


\section{DISCUSSION}

This case control study had been carried out to assess the changes that occur in RBC indices and biochemical parameters of mineral bone disorders in patients with ESRD on regular hemodialysis.

Our study showed that $\mathrm{RBC}$ count, $\mathrm{Hb}$ and hematocrit were significantly lower in hemodialysis patients compared to the control group $(\mathrm{P}<0.001$ for all). This is consistent with the results of Muhammad et al. ${ }^{(6)}$ and Yassein et al. ${ }^{(7)}$ who reported significantly lower levels of $\mathrm{Hb}, \mathrm{RBC}$ count and hematocrit in chronic renal failure patients as compared to the control group. Anemia was also prevalent in patients receiving dialysis in studies done by Khadayate $\boldsymbol{e t}$ al. ${ }^{(8)}$ and Keshk et al. ${ }^{(9)}$. Anemia is a common complication in hemodialysis patients because of suppression of erythropoiesis, loss of RBC during dialysis process to some extent, iron deficiency, vitamin B12 or folate deficiency and bleeding caused by platelet dysfunction ${ }^{(\mathbf{1 0})}$.

The present study showed no statistically significant differences in $\mathrm{MCV}, \mathrm{MCH}$ and $\mathrm{MCHC}$ between the two studied groups and this is in line with the results obtained by Hala et $\boldsymbol{a l} .{ }^{(11)}$. Our study revealed that RDW was significantly higher in hemodialysis patients as compared to the control group. Similarly, Abdel-Moneim et al. (12) reported a significantly increase in RDW in renal dysfunction patients. Elevated RDW indicated a high variability of red cell size, which is a marker of ineffective erythropoiesis ${ }^{(13)}$.

Alghythan and Alsaeed (14) described a significant decline $\mathrm{MCH}$ in hemodialysis patients as compared to the control group and non-significant differences in MCV, MCHC and RDW. On the other hand; Muhammad et al. ${ }^{(6)}$ reported a significant decrease in MCHC and RDW, and a significant increase in $\mathrm{MCV}$ in hemodialysis patients as compared to the control group but no significant difference in $\mathrm{MCH}$. George et al. ${ }^{(15)}$ reported no significant differences between CKD group and control group as regards MCV, $\mathrm{MCH}, \mathrm{MCHC}$ and RDW. The discrepancies in the results of the studies regarding $\mathrm{MCV}, \mathrm{MCH}, \mathrm{MCHC}$ and RDW can be attributed to dissimilarities in etiologies of anemia in patients involved in different studies.

Regarding biochemical parameters of mineral bone disorders, the present study showed that calcium $\mathrm{Alb}_{\mathrm{lb}}$ was significantly lower in hemodialysis patients as compared to the control group while, both serum phosphate and serum iPTH were significantly higher in hemodialysis patients as compared to the control group.

Although hypocalcemia is a late consequence in CKD, altered mineral metabolism starts much earlier and manifests as secondary hyperparathyroidism. The main cause is reduced synthesis of 1,25dihydroxyvitamin D in the kidney, which stimulates PTH secretion both directly and indirectly through decreased intestinal calcium absorption. Furthermore, there is reduced calcium mobilization from bone due to decreased bone sensitivity to PTH along with calcitriol deficiency (16). The decreased synthesis of 1,25dihydroxyvitamin $\mathrm{D}$ in patients with CKD is due to inhibition of 25-hydroxy vitamin D 1a-hydroxylase in the kidney by the increased fibroblast growth factor-23 (FGF-23) level and hyperphosphatemia (both are caused by impaired renal excretion of phosphate). This is compounded by renal tissue loss and subsequent decreased availability of the enzyme. Hyperphosphatemia also stimulates PTH release ${ }^{(17)}$.

In 2018, Bazeed et al. ${ }^{(\mathbf{1 8 )}}$ who studied 20 normal subjects, 60 CKD patients (stage 2, 3 and 4), and 40 ESRD patients on maintenance hemodialysis found that mean serum calcium was significantly lower in ESRD patients $(8.06 \pm 0.62 \mathrm{mg} / \mathrm{dl})$ in comparison with nondialysis CKD patients $(9.24 \pm 1.13 \mathrm{mg} / \mathrm{dl})$ and normal subjects $(9.02 \pm 0.35 \mathrm{mg} / \mathrm{dl})$ with a P-value $<0.001$, but there was no significant difference between non-dialysis CKD patients and normal subjects in mean serum calcium. Also, they found that mean serum phosphate was significantly higher in ESRD patients (5.74 \pm 1.28 $\mathrm{mg} / \mathrm{dl})$ as compared to non-dialysis CKD patients (4.61 $\pm 0.67 \mathrm{mg} / \mathrm{dl})$ and normal subjects $(4.50 \pm 0.28 \mathrm{mg} / \mathrm{dl})$ with a P-value $<0.001$, but no significant difference was found in mean serum phosphate between non-dialysis CKD patients and normal subjects. The results of our study were also similar to those of Warade and

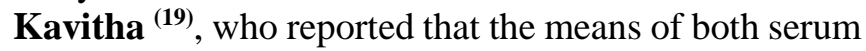
phosphate and serum iPTH were significantly higher in hemodialysis patients when compared with the control group $(\mathrm{P}<0.001)$. Additionally, Sliem et al. ${ }^{(20)}$ found that the mean serum iPTH in the hemodialysis group was $296.3 \pm 56.1 \mathrm{pg} / \mathrm{ml}$, and in the control group it was $51.9 \pm 8.7 \mathrm{pg} / \mathrm{ml}$, with a P-value $<0.001$.

Concerning the relationship between anemia and serum $\mathrm{iPTH}$, the present study showed that $\mathrm{Hb}$ was inversely correlated with serum iPTH in the hemodialysis group whereas in the control group, there was no significant correlation between $\mathrm{Hb}$ and serum iPTH. This was in agreement with the studies conducted by Keshk et al. ${ }^{(9)}$ and Penne et al. ${ }^{(21)}$. On the other hand; Sliem et al. ${ }^{(20)}$ reported a significant negative correlation between $\mathrm{Hb}$ and $\mathrm{PTTH}$ in the hemodialysis patients and the control group. Although Adhikary $\boldsymbol{e t}$ al. ${ }^{\text {(22) }}$ reported a weak negative correlation between $\mathrm{Hb}$ and serum iPTH in hemodialysis patients, it did not attain a statistical significance $(\mathrm{P}=0.334)$. In 2020, Azeem et al. ${ }^{(23)}$, in their study on 110 patients undergoing maintenance hemodialysis, reported a significant association between hyperparathyroidism and anemia.

Secondary hyperparathyroidism is a less recognized, but probably essential cause of anemia in CKD patients ${ }^{\text {(24). }}$. PTH has been recognized as a uremic toxin that potentially inhibits erythropoietin synthesis, 
shortens RBCs survival, and causes myelofibrosis and thus decreases hematopoiesis. ${ }^{(25)}$ Also, there are some studies which support an increase in osmotic fragility of RBCs due to hyperparathyroidism in dialysis patients and thus leading to anemia ${ }^{(26)}$. The possible role of PTH in renal anemia has been supported by recent clinical studies that showed that the treatment of secondary hyperparathyroidism using vitamin $\mathrm{D}$ receptor activators, calcimimetics, or parathyroidectomy leads to improvement of anemia ${ }^{(24)}$.

In our study, there was a significant negative correlation between serum phosphate level and $\mathrm{Hb}$ in both hemodialysis and control groups. In line with our result, the studies conducted by Kimata et al. ${ }^{(5)}$ and Amnuay et al. ${ }^{(27)}$ showed that higher serum phosphorus levels were associated with low hemoglobin levels in hemodialysis patients. On the other hand; Fahmy et al. (28) reported no significant correlation between $\mathrm{Hb}$ and ionized calcium in hemodialysis patients. Tran et al. ${ }^{(29)}$ reported a significant negative correlation between serum phosphate level and $\mathrm{Hb}$ in early CKD patients and in individuals with normal kidney function. Moreover, a study assessing the National Health and Nutrition Examination Survey population revealed that serum phosphate level higher than $4.4 \mathrm{mg} / \mathrm{dl}$ was associated with mild anemia in participants with normal kidney function ${ }^{(30)}$.

Several mechanisms for explaining the association between hyperphosphatemia and anemia have been proposed for patients with CKD and ESRD. Kovesdy et al. ${ }^{(31)}$ suggested that hyperphosphatemia may lead to higher polyamines production, which can behave as uremic toxins inhibiting erythropoiesis. In the presence of hyperphosphatemia, vascular calcification can occur within arteries including the renal arteries, which may finally lead to erythropoietin deficiency and anemia ${ }^{(32)}$. Hyperphosphatemia can also result in decreased vitamin D synthesis, leading to hypocalcemia and hyperparathyroidism. ${ }^{(33)}$ Hyperparathyroidism, in sequence, has been shown to inhibit erythropoiesis, induce hemolysis and produce bone marrow fibrosis ${ }^{(25)}$.

On the other hand; the mechanisms underlying the association between hyperphosphatemia and anemia in early CKD patients and in persons with normal kidney function are less clear. Emerging data have indicated that FGF-23 plays a crucial role in phosphate and vitamin D metabolism (24). Hyperphosphatemia itself has been shown to raise FGF-23 levels, which in turn is associated with suppression of klotho ${ }^{(34)}$. Low klotho levels, in murine models, were associated with poor outcomes including premature aging, cell toxicity, and vascular calcifications ${ }^{(35)}$. Low klotho levels also result in vitamin D deficiency which in itself has been implicated with anemia ${ }^{(29)}$.

The present study showed no significant correlation between $\mathrm{Hb}$ and calcium $\mathrm{Alb}$ in the hemodialysis group as well as in the control group. In concordance with our result, Amnuay et al. (27) and Fahmy et al. $^{(28)}$ reported no significant association between $\mathrm{Hb}$ and serum calcium in hemodialysis patients. On the other hand; Kimata et al. ${ }^{(5)}$ reported that an increase in patient calcium Alb $_{\text {over }} 4$ months in hemodialysis patients was associated with a significant rise in patient $\mathrm{Hb}$ level of $0.17 \mathrm{~g} / \mathrm{dl}$ per each $1 \mathrm{mg} / \mathrm{dl}$ rise in calcium Alb. $_{\text {. }}$

\section{CONCLUSION}

In conclusion, this study showed that hemodialysis patients are at increased risk of anemia, hypocalcemia, hyperphosphatemia and hyperparathyroidism. Serum phosphate and iPTH were inversely correlated with $\mathrm{Hb}$ levels in hemodialysis patients and this should urge the clinicians to closely monitor these parameters during management of anemia in such patients.

\section{REFERENCES}

1. Jankowski J, Floege J, Fliser D et al. (2021): Cardiovascular disease in chronic kidney disease. Circulation, 143: 1157-1172.

2. Denic A, Glassock RJ, Rule AD (2016): Structural and functional changes with the aging kidney. Adv Chronic Kidney Dis., 23: 19-28.

3. Babitt J, Lin $\mathbf{H}$ (2012): Mechanisms of anemia in CKD. J Am Soc Nephrol., 23:1631-4.

4. Vassalotti JA, Centor R, Turner BJ et al. (2016): Practical approach to detection and management of chronic kidney disease for the primary care clinician. The American journal of medicine, 129 (2): 153-162.e7.

5. Kimata N, Akiba T, Pisoni RL et al. (2005): Mineral metabolism and hemoglobin concentration among haemodialysis patients in the Dialysis Outcomes and Practice Patterns Study (DOPPS). Nephrol Dial Transplant, 20: 927-935.

6. Muhammad A, Zeb MA, Ullah A et al. (2020): Effect of haemodialysis on hematological parameters in chronic kidney failure patients Peshawar-Pakistan. Pure Appl. Biol., 9 (1): 1163-1169.

7. Yassein R, Alseedig N, Abdallah $S$ et al. (2016): Hematological parameters among Sudanese patients with chronic kidney failure. Int J of Res., 4 (1): 50-54.

8. Khadayate R, Sahu P, Sahu S et al. (2020): Study of hematological profile in chronic renal failure patients on hemodialysis in a Tertiary Care Hospital. Int J Health Sci Res., 10 (12): 1-7.

9. Keshk R, Esheba N, Salah W et al. (2016): Relation between intact parathyroid hormone and hemoglobin level in chronic kidney disease patients on hemodialysis. Tanta Med J., 44: 170-175.

10. Cernaro V, Coppolino G, Visconti L et al. (2019): Erythropoiesis and chronic kidney disease-related anemia: From physiology to new therapeutic advancements. Med Res Rev., 39 (2): 427-460.

11. Hala O, Zeinab H, Khalda M (2014): Assessment of complete blood count of chronic renal failure patients under hemodialysis. Journal of Science and Technology, 15 (1): 9-13. 
12. Abdel-Moneim A, Mahmoud B, Nabil A et al. (2019): Correlation between oxidative stress and hematological profile abnormalities in diabetic nephropathy. Diabetes \& Metabolic Syndrome, 13 (4): 2365-2373.

13. Al-Kindi S, Refaat M, Jayyousi A et al. (2017): Red cell distribution width is associated with all-cause and cardiovascular mortality in patients with diabetes. BioMed research international, 2017:5843702.

14. Alghythan A, Alsaeed A (2012): Hematological changes before and after hemodialysis. Scientific Research and Essays, 7: 490-497.

15. George C, Matsha T, Erasmus $R$ et al. (2018): Haematological profile of chronic kidney disease in a mixed-ancestry South African population: a cross sectional study. BMJ Open, 8: e025694.

16. Cunningham J, Locatelli F, Rodriguez M (2011): Secondary hyperparathyroidism: pathogenesis, disease progression, and therapeutic options. Clin J Am Soc Nephrol., 6: 913-921.

17. O'Neill W (2016): Targeting serum calcium in chronic kidney disease and end-stage renal disease: is normal too high?. Kidney international, 89 (1): 40-45.

18. Bazeed M, Allam M, Bakeer M et al. (2018): A comparative study of platelet parameters in chronic kidney disease, end stage renal disease patients undergoing hemodialysis and healthy individuals. The Egyptian Journal of Hospital Medicine, 71 (6): 34293433.

19. Warade P, Kavitha $R$ (2015): Secondary hyperparathyroidism in chronic kidney disease. IAIM., 2: $42-48$.

20. Sliem H, Tawfik G, Moustafa F et al. (2011): Relationship of associated secondary hyperparathyroidism to serum fibroblast growth factor23 in end stage renal disease: a case control study. Indian J Endocrinol Metab., 15: 105-109.

21. Penne L, Neelke C, Muriel P et al. (2011): Role of residual renal function in phosphate control and anemia management in chronic hemodialysis patients. Clin $\mathrm{J}$ Am Soc Nephrol., 6: 281-289.

22. Adhikary P, Pokhrel A, Yadava K et al. (2015): Relation between serum intact parathyroid hormone level and hematocrit in chronic kidney disease patients. Kathmandu Univ Med J., 13: 220-223.

23. Azeem S, Haroon A, Alam I et al. (2020): Frequency of anemia in patients with increased level of parathyroid hormone among patients on maintenance hemodialysis. Professional Med J., 27 (6): 1255-1258.
24. Tanaka M, Komaba H, Fukagawa M (2018): Emerging association between parathyroid hormone and anemia in hemodialysis patients. Therapeutic Apheresis and Dialysis, 22 (3): 242-245.

25. Gallieni M, Corsi C, Brancaccio D (2000): Hyperparathyroidism and anemia in renal failure. The American Journal of Nephrology, 20 (2): 89-96.

26. Wu S, Jeng F, Wei S et al. (1998): Red blood cell osmotic fragility in chronically hemodialyzed patients. Nephron, 78 (1): 28-32.

27. Amnuay K, Srisawat N, Wudhikarn K et al. (2019): Factors associated with erythropoiesis-stimulating agent hyporesponsiveness anemia in chronic kidney disease patients. Hematology Reports, 11: 8183.

28. Fahmy A, El-Naggar A, Al-Gazaly G et al. (2018): Evaluation of anemia among patients with end stage renal disease on hemodialysis in Al-Gharbia Governorate. The Medical Journal of Cairo University, 86: 2349-2359

29. Tran L, Batech $M$, Rhee $C$ et al. (2016): Serum phosphorus and association with anemia among a large diverse population with and without chronic kidney disease. Nephrol Dial Transplant, 31: 636-645.

30. Wojcicki J (2013): Hyperphosphatemia is associated with anemia in adults without chronic kidney disease: results from the National Health and Nutrition Examination Survey (NHANES): 2005-2010. BMC Nephrol., 14, 178.

31. Kovesdy C, Mucsi I, Czira M et al. (2011): Association of serum phosphorus level with anemia in kidney transplant recipients. Transplantation, 91: 875882.

32. Kuroo M (2014): New developments in CKD-MBD. Why is phosphate overload harmful?. Clin Calcium, 24: 1785-1792.

33. Blaine J, Chonchol M, Levi M (2015): Renal control of calcium, phosphate, and magnesium homeostasis. Clin J Am Soc Nephrol., 10: 1257-1272.

34. Krajisnik T, Olauson $H$, Mirza M et al. (2010): Parathyroid Klotho and FGF-receptor 1 expression decline with renal function in hyperparathyroid patients with chronic kidney disease and kidney transplant recipients. Kidney Int., 78: 1024-1032.

35. Morishita K, Shirai A, Kubota M et al. (2001): The progression of aging in klotho mutant mice can be modified by dietary phosphorus and zinc. J Nutr., 131: 3182-3188. 